\title{
Development and 3D Printing of an ABS Ergonomic Handle for Medical Use A case study
}

\author{
DANIEL VLASCEANU ${ }^{1}$, FLORIN BACIU ${ }^{1 *}$, DIANA POPESCU ${ }^{1}$, ANTON HADAR ${ }^{1,2}$, RODICA MARINESCU ${ }^{3}$ \\ ${ }^{1}$ University Politehnica of Bucharest, 313 Splaiul Independentei, 060042, Bucharest, Romania \\ ${ }^{2}$ Academy of Romanian Scientists, 125 Calea Victoriei, 010071, Bucharest, Romania \\ ${ }^{3}$ Colentina Clinical Hospital, 19-21 Stefan cel Mare Road, 020125, Bucharest, Romania
}

\begin{abstract}
This paper presents a study undertaken following the collaboration between specialists in two multidisciplinary fields, namely engineering and medicine. It was aimed at solving a practical problem by developing of a handle for use in orthopedic surgery. Specific engineering tools, knowledge and processes and methods were used for accomplishing this task. Tailoring devices according to surgeons preferences for ensuring an ergonomic use is an important criterion alongside functional and sterilization requirements, cost and fabrication time, 3D printing representing a feasible manufacturing solution as this research proves. The article details the steps required to complete the final product: design and redesign, numerical analysis, prototypes manufacturing and testing. To perform the numerical analysis that highlights the device mechanical behavior, finite element method was used in assessing different handle designs.
\end{abstract}

Keywords: 3D printing, medical devices, finite element method, design

The use of Additive Manufacturing (or 3D Printing) in the medical field starts to become a common practice if one considers the increasing number of scientific papers [1$3]$, research projects and patents $[4,5]$, as well as the number of applications developed by universities and/or specialized companies $[3,6]$.

Additive Manufacturing (AM) is currently used [7-8] for manufacturing medical replicas, patient specific templates, implants, surgical tools, drugs, dosage forms, etc., but also for 3D bio-printing applications. Literature studies and reviews showed that the focus of today's researches is put more on designing, manufacturing and testing functional products and less on building medical phantoms used for visualization, communication or teaching activities. Functional products are developed based on medical needs, but the type of building materials, AM process and AM process parameters, sterilization conditions, specific design for AM rules should also be considered.

Orthopedics is one medical field requiring the development of functional products such as surgical guides [9], instrumentations/tools, implants or prostheses, manufactured from metals or plastics using different AM processes. AM advantages in terms of fast customization to patient data and to the medical necessity, geometric freedom, shorter lead time, can be all exploited for obtaining useful products which can decrease the surgical time, reduce some of the costs, improve intervention accuracy by better fitting patients' specific needs.

However, despite these advantages and the increased use of AM in medicine, 3D-printed instrumentation (scalpels, forceps, needle drivers, handles, clamps, hemostats) represents a relatively new type of application [10-12]. In this context, the current article adds knowledge to the field by presenting the design and manufacturing process of an ergonomic handle for an acetabular cemented cup insertion instrument, aimed at solving a practical need.

For medical instrumentation, tailoring the device (customization versus mass production) according to surgeon preferences in terms of ergonomics use is an important criterion along functional and sterilization requirements, cost and manufacturing time.

Modern cementing techniques are related with long term survival in cemented total hip arthroplasty (THA), for assuring a good quality cementation and, as a consequence, for a good implant bone fixation and stability. This is particularly important on the acetabular side where the anatomy make difficult to reach outa correct pressurization technique. Cement interdigitating is extremely important in achieving good cement fixation by applying a constant pressure to the acetabulum and cement for 1 to 3 min using a pressurizer. The next surgical step is to remove the pressurizer and insert the cup into acetabulum containing the pressurized cement, set into the correct position and a pressure is maintained until final sets of the cement occur. In this stage, the surgeon applies constant and continuous pressure force through the acetabulum-cement cup construct for 3-4 min at 80-100N, followed by 7-9 min at 25-30N [13-15]. This is done using an acetabular cemented cup insertion instrument (inserter), which in the most cases, has a handle with a cylindrical shape. This shape lacks ergonomics and predispose surgeon to early fatigue, potentially leading to pressure loosening and consequently interfering with proper cement technique.

Therefore the need to design and manufacture a cost effective, ergonomic handle which can adapt to inserters with cylindrical grips/handgrips, be easy to place and remove off the instrument, not be bulky and, obviously, be sterilizable.

\section{Experimental part \\ Material and method \\ Design process}

Starting with the medical need and with the dimensions of the inserter grip, a handle was designed in CATIA V5 (fig.1). It includes an asymmetrical T like gripping zone shaped according to surgeon preferences, hand dimensions and handle and instrument position during use, and a cylindrical zone with an internal channel allowing the coaxial placement of the handle along the inserter

\footnotetext{
*email: florin.baciu@upb.ro, Phone: 0726268078
} 
handgrip. For avoiding the rotation between the handle and the inserter grip, a slot is provided in order to reduce the internal diameter using a screw-nut fixation.

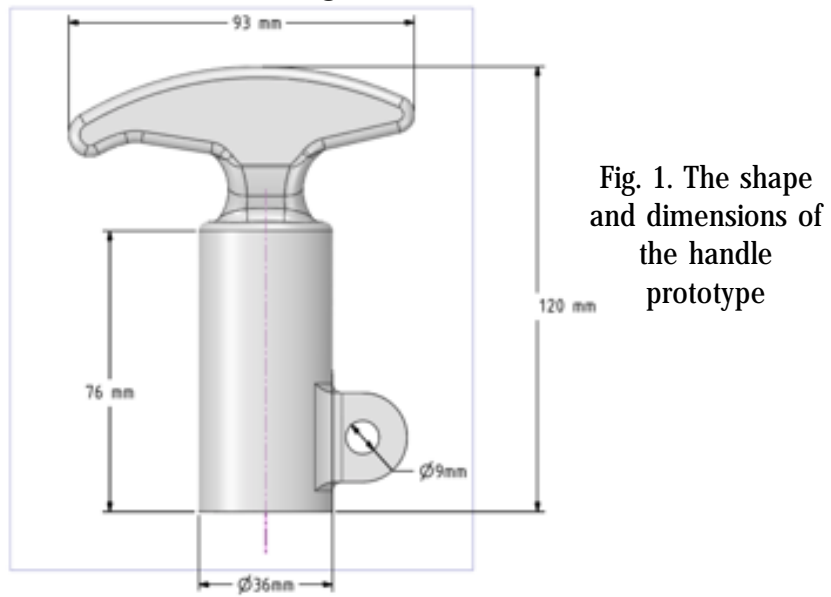

3D printing process

The material used for the designed device is a thermoplastic plastic commonly used in 3D Printing, namely Acrylonitrile-Butadiene-Stirene (ABS). ABS copolymer contains chemical radicals with proprietary properties that generallylead to applications in various fields such as medicine, automotive, aeronautics, fine mechanics, and so on.

The mechanical properties of this material are presented in literature [16-21]. However, in each research these are determined based on testing specimens manufactured by varying different process parameters settings and analyzing their influence over, mainly, tensile or compressive strength [18]. Therefore, for this case study, the mechanical properties values were those determined in a previous research [20]. Anisotropy is specific to 3D printing $[16-18,21]$ and it should be taken into account when simulating prints behavior using software tools. This aspect was also considered in our study.

Experimental testing aimed at determining mechanical and elastic properties was performed on a $100 \mathrm{kN}$ INSTRON 8800 Universal Hydraulic machine for traction tests (from ambient to maximum temperature of $1000^{\circ} \mathrm{C}$ ), three-point bending, compression and tests of fatigue.

Following tests and after processing experimental data, the characteristic curves of the material under compression were obtained [20]. The results of experimental investigations were used also in this research as the handle prototypes were manufactured in the same manufacturing conditions, i.e. on the same machine, with the same process parameter settings and from $A B S$ material from the same producer.

For 3D printing the handle, Mojo printer from Stratasys and ABS material were used. The value of layer height was $0.178 \mathrm{~mm}$; the infill was set to solid $(100 \%)$, while the support structure was set to Smart. The handle in figure 1 was printed in horizontal or vertical position, with several variations also on slot dimensions and of the fastening zone. The manufacturing times were: $9 \mathrm{~h} 39 \mathrm{~min}$ for horizontal position $\left(108 \mathrm{~cm}^{3}\right.$ and $\left.18.4 \mathrm{~cm}^{3}\right)$ and $12 \mathrm{~h} 4 \mathrm{~min}$ for vertical position $\left(108 \mathrm{~cm}^{3}\right.$ and $\left.20.1 \mathrm{~cm}^{3}\right)$.

The building orientation is a very important aspect, influencing the mechanical properties of the 3D print. Researches in this field related to the influence of printing orientation, infill and raster orientation on the compression strength [16-19] showed that manufacturing the part at $100 \%$ infill, $45 \%-45^{\circ}$ raster angle and ensuring that the compressive load is carried axial (perpendicular to the building direction) and not transversal can provide optimal compressive strength (the transverse specimen had 15 percent lower compressive strength than the axial specimen [17])

Handles have been 3D printed in two orientations: longitudinal and transverse, as it can be seen in figures 2
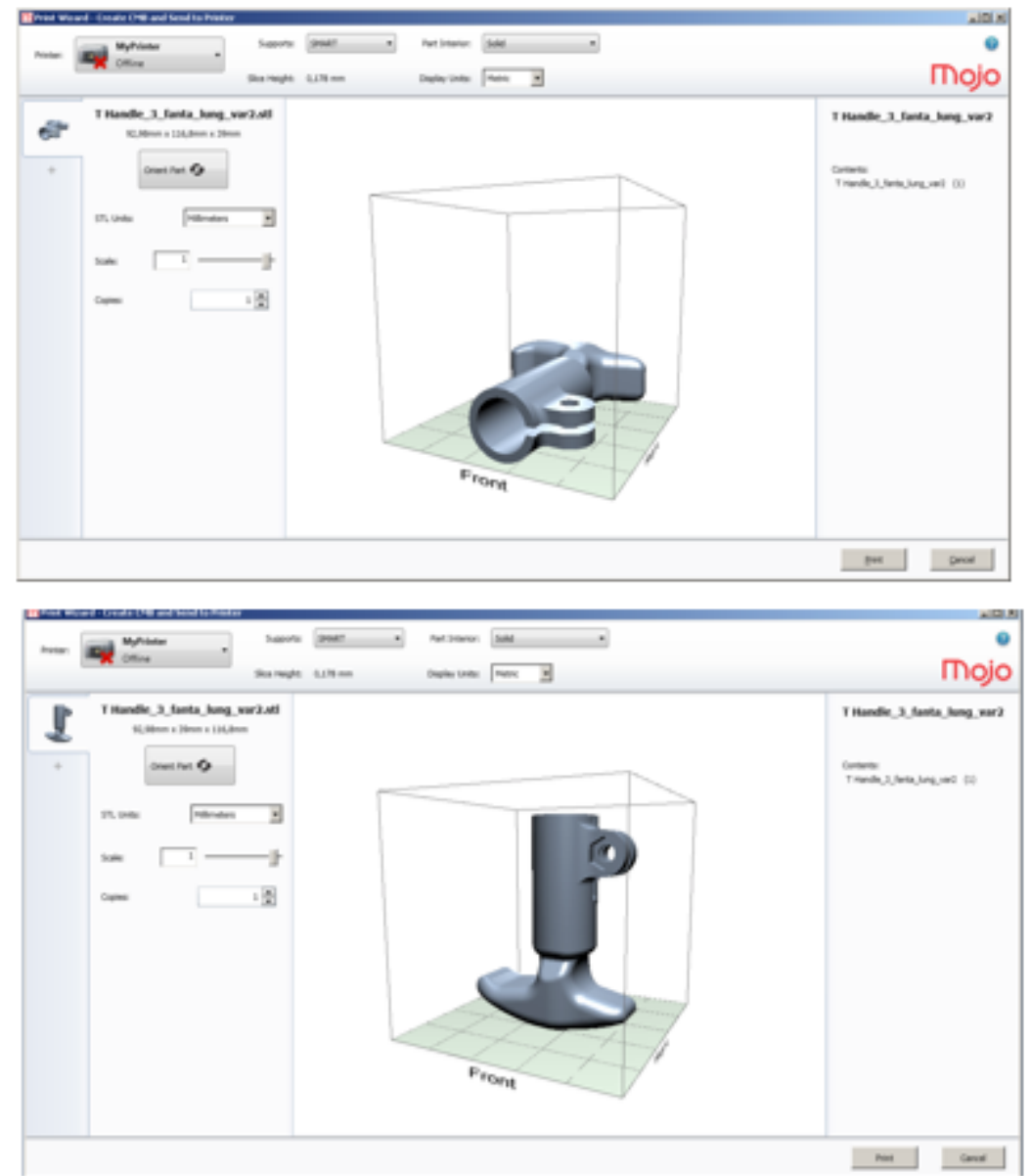

Fig. 2. Handle 3D printed in longitudinal directions 
and 3. The physical model of the prototype is presented in figure 4.

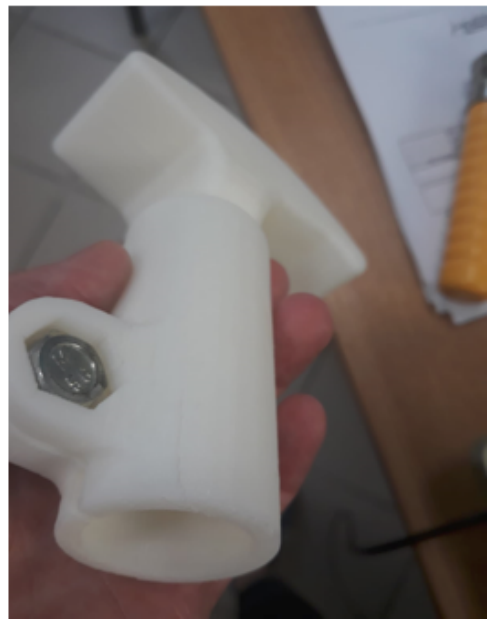

Fig. 4. Handle physical prototype

Numerical analysis

The initial design was subjected to finite element analysis (FEA) using ANSYS software. The idea was to analyze the effect on handle strength when prescribing different dimensions for the slot (length), as well as different distances between the geometrical features/ears of the fastening zone.

The geometrical 3D model was imported into ANSYS program, a numerical analysis program that uses the finite element method (FEM) as a solver. The purpose of numerical simulation was to determine the state of stress and deformation in the model according to the mechanical loadings to which it is subjected.

For the numerical calculation the 3D geometric model was meshed with three-dimensional finite elements of the SOLID type (fig. 5).

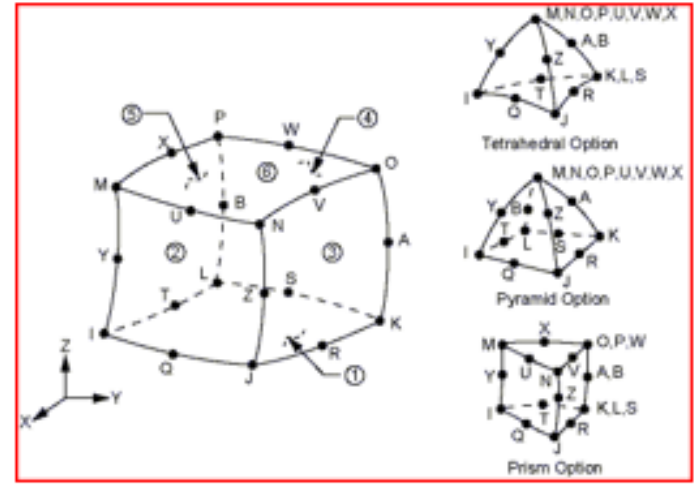

Fig. 5. SOLID187 geometry

After the meshing process (fig. 6), the whole model was divided into a finite network of elements consisting of 8914 nodes and 4882 elements. For the application of loads, the compressive force was calculated as $1000 \mathrm{~N}$, equivalent to a mass of $100 \mathrm{Kg}$.

In terms of bonding conditions, considering that handle covers a medical instrument used in the implantation procedure, it was considered the inner handle is blocked in all directions so the entire inner surface is not giving any movement (all degrees of freedom were canceled). The clamping screw has not been modeled, but the clamping effect has been simulated by imposing $1 \mathrm{~mm}$ left-right directions, as it can be seen in figure 7 .

\section{Testing}

Different designs of handles were tested by placing them on the acetabular cemented cup insertion inserter and fixing them with screw-nut. Observations were made regarding the modifications suffered by the handles when subjected to different loads. After tests, one design was

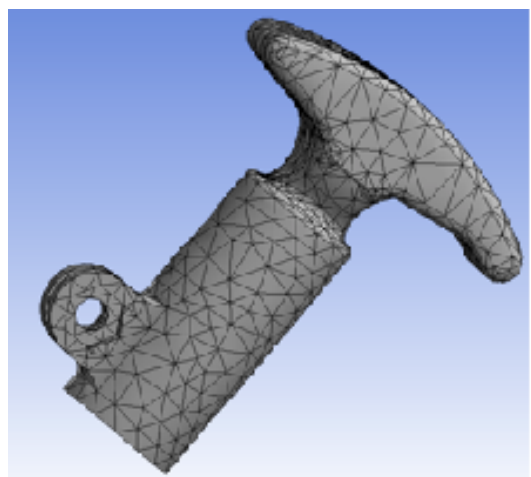

\begin{tabular}{|c|c|c|c|}
\hline \multicolumn{3}{|c|}{ Drtaik nf "Mrsh" } & 7 \\
\hline \multirow{2}{*}{$\square$} & \multicolumn{3}{|l|}{ Display } \\
\hline & Display style & Dody Color & \\
\hline \multirow[t]{4}{*}{$\theta$} & \multicolumn{2}{|l|}{ Detau its } & \\
\hline & Mhysics Hraterence & Mechanical & \\
\hline & $\square$ Relevancs & 0 & \\
\hline & Clement Orde: & Projram Controlled & \\
\hline+5 & \multicolumn{2}{|l|}{ Sixily } & \\
\hline+1 & \multicolumn{3}{|l|}{ Quality } \\
\hline (1) 1 & \multicolumn{3}{|l|}{ Inflation } \\
\hline+1 & \multicolumn{3}{|l|}{ Advanced } \\
\hline \multicolumn{4}{|c|}{ Statistics } \\
\hline & $\square$ Nodes & 8914 & \\
\hline & $\square$ Elements & 4382 & \\
\hline
\end{tabular}

Fig. 6. Handle meshed model

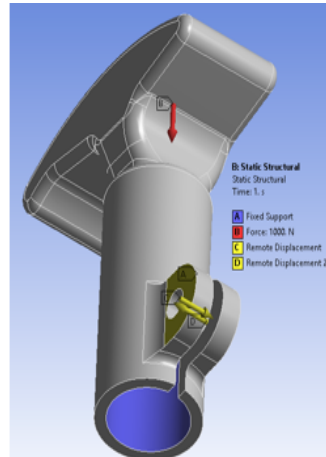

Fig. 7. Application of external loads and constraints

considered optimal as strength, functionality and ergonomics, sterilized and used in surgery (fig. 8).

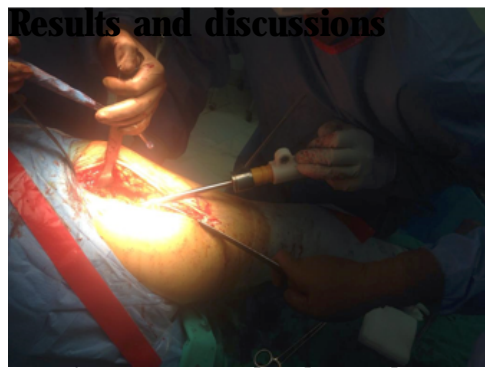

Fig. 8. Handle used in surgery

After setting the boundary conditions, a linear static structural analysis was performed in order to evaluate the structural integrity of model. This was chosen for determining the stress state that propagates in the model, for calculating the normal stress on the direction of application of the compressive force and for calculating the equivalent stress using the vonMises criterion.

Analyzing the figure 9 , it was noticed that the maximum equivalent stresses are concentrated in the gripping area of the handle on the medical instrument. The maximum value of the equivalent stresses was 181MPa. Comparing this value to the compressive strength value of $A B S$ material used for manufacturing the handle, the conclusion was that in that area the structure loses its structural integrity and the repeated use of the handle can determine breaking. This observation was confirmed during experimental handle tests (fig. 10). After successive tests 
on physical handles, including tightening and releasing of screw-nut and applying different compression forces, a splitting of the layers happened in the mentioned area, for one handle design.

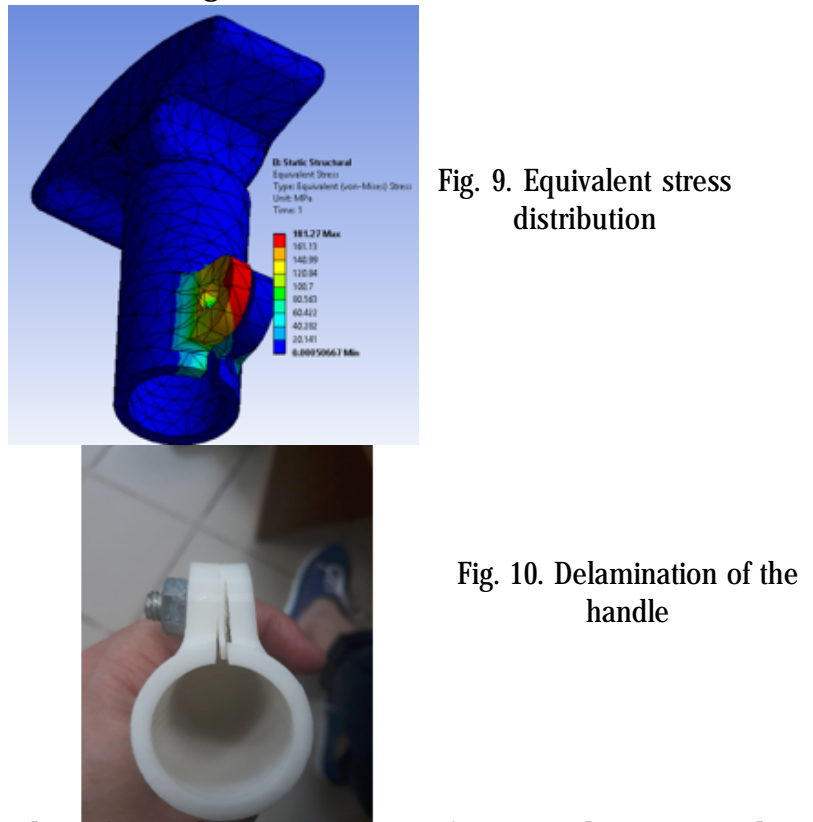

Therefore, the next stage of research consisted in optimizing the model and strengthening the screw clamping area. In this sense, the handle was redesigned to optimize the area of the screw fastening and the slot length. After resuming the numerical analysis, the following results were obtained which are shown in figure 11.

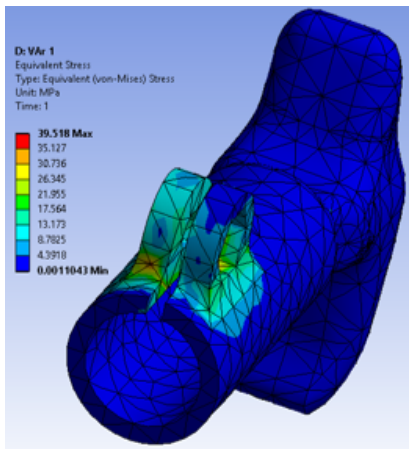

Fig. 11. Equivalent stress distributions in optimized handle

Analyzing the results presented in figure 11 it is found that the maximum value of the equivalent stress is less than the compressive strength of the material used in the manufacture of the handle.

\section{Conclusions}

Several conclusions could be drawn from the case study presented in this paper:

Attention should be paid when designing for 3D printing by taken into account that the mechanical behavior is influenced also by the building orientation;

Numerical analysis can be used as an efficient method for determining and improving the mechanical behavior of 3D printing objects;

The development process presented can be applied to other 3D printing devices. However, one should remember that tensile and compressive strength, for instance, are dependent on process parameters and 3D printer. Therefore, their values should be determined on testing specimens before FEM analysis.

Further research will be focused on topological optimization of the handle using ANSYS for reducing its weight and benefiting of one 3D printing technology advantage, i.e. to manufacture complex shapes parts, very difficult or costly to be manufactured using traditional technologies. Reducing handle weight will also impact the material consumption, costs and manufacturing time, considering that $3 \mathrm{D}$ printing the handle is currently a long process.

\section{References}

1. JIN, Y., LI, X, CAMPBELL, R.I., JI, S., Visualizing the hotspots and emerging trends of $3 \mathrm{D}$ printing through scientometrics, Rapid Prototyping J ournal, 24(5), 2018, pp. 801-812

2. GUPTA, B.M., DHAWAN, S.M., Three Dimensional (3D) Printing: A Scientometric Assessment of Global Publications Output during 200716, DESIDOC Journal of Library and Information Technology, 38(4), 2018, pp. 238-245

3. POPESCU, D., LAPTOIU, D., Rapid prototyping for patient-specific surgical orthopaedics guides: A systematic literature review, Proceedings of the Institution of Mechanical Engineers Part $\mathrm{H} J$ ournal of Engineering in Medicine, 230(6), 2016, pp. 495-515

4. WOHLERS report, ISBN 978-0-9913332-3-3, available at https:// wohlersassociates. com/2017report.htm

5. HORNICK, J., 3D printing patent landscape, available at https:// 3dprint.com/181207/3d -printing-patent-landscape

6. SME, Medical Additive Manufacturing/3D Printing Annual Report 2018, available at: https://www.sme.org/medical-am3dp

7. RYBICKI, F. ., GRANT, G.T. (eds.), 3D Printing in Medicine: A Practical Guide for Medical Professionals, 2017, ISBN-13: 978-3319619224, Springer

8. SRIVATSAN, T.S., SUDARSHAN, T.S., Additive Manufacturing Innovations, Advances and Applications, Chapters 14-16, 2015, CRC Press

9. POPESCU, D., LAPTOIU, D., BOTEZATU, I., MARINESCU, R., Design and $3 D$ printing customized guides for orthopaedic surgery - lessons learned, Rapid Prototyping J ournal, 24(5), 2018, pp. 901-913

10. GEORGE, M., AROOM, K.R., HAWES, H.G., GILL, B.S., LOVE, J., 3D printed surgical instruments: the design and fabrication process, World J Surg, 41(1), 2017, pp. 314-319

11. WONG, J.Y., PFAHNL, A.C., 3D printing of surgical instruments for long-duration space missions, Aviat Space Environ Med, 85(7), 2014, pp. $758-763$

12. KONDOR, S., Personalized surgical instruments, J Med Devices ASME, 7(3), 2013 WADIA, F., MALIK, M.H.A., LEONARD, D., PORTER, $M$. L., Cement pressurisation in the acetabulum, International Orthopaedics, 30(4), 2006, pp. 237-242

14. SMITH, B. N., Improved acetabular cementing techniques, Master thesis, 2007, Queensland University of Technology, available at: https:/ /eprints.qut.edu.au/16560/1/Bjorn_N._Smith_Thesis.pdf

15. BREUSCH, S., MALCHAU, H., The Well-Cemented Total Hip Arthroplasty: Theory and Practice, 2005, Springer

16. HERNANDEZ, R., SLAUGHTER, D., WHALEY, D., TATE, J ., ASIABANPOUR, B., Analyzing the tensile, compressive, and flexural properties of 3D printed ABS $P 430$ plastic based on printing orientation using fused deposition modeling, Solid Freeform Fabrication 2016, Proceedings of the $26^{\text {th }}$ Annual International Solid Freeform Fabrication Symposium, 2016, pp. 939-950

17. AHN, S.-H., MONTERO, M., ODELL, D., ROUNDY, S., WRIGHT, P.K., Anisotropic material properties of fused deposition modeling ABS, Rapid Prototying J ., 8(4), 2002, pp. 248-257

18. POPESCU, D., ZAPCIU, A., AMZA, C., BACIU, F. MARINESCU, R. FDM process parameters influence over the mechanical properties of polymer specimens: A review, Polymer Testing, Vol. 69, 2018, pp. 157-166

19. SOOD, K., OHDAR, R.K., MAHAPATRA, S.S., Experimental investigation and empirical modelling of FDM process for compressive strength improvement, J. Adv. Res., Vol. 3, 2012, pp. 81-90

20. POPESCU, D., VLASCEANU, D., CURSARU, L., BACIU, F., HADAR, A., Low-temperature sterilization influence on fused deposition modelling parts, Proceedings in Manufacturing Systems, 11(3), 2016, pp.151-158

21. LEE, C.S., KIM, S.G., AHN, S.H., Measurement of anisotropic compressive strength of rapid prototyping parts, Journal of Materials Processing Technology, 187-188, 2007, pp. 627-630 